\title{
Optimized Extraction of Oleoresin Capsicum and Analytical Method Validation for Capsaicin using HPLC
}

\author{
Shubham Sharma ${ }^{1}$, Ranjit Singh Kushwaha', Subh Naman'1, Umesh Kumar Patil' ${ }^{2}$ Ashish Baldi1,*
}

'Department of Pharmaceutical Sciences and Technology, Maharaja Ranjit Singh Punjab Technical University, Bathinda, Punjab, INDIA.

${ }^{2}$ Department of Pharmaceutical Sciences, Dr. Harisingh Gour Vishwavidyalaya, Sagar, Madhya Pradesh, INDIA.

\begin{abstract}
Background: Capsaicin, the main active constituent of oleoresin capsicum present in capsicum fruits, is responsible for their pungency and color. Capsaicinoids is an important phytoconstituents and hence exported for various benefits. Hypothesis of work: The process of extraction of oleoresin capsicum by reflux method was to be optimized using in terms of their percentage yield. Further $\mathrm{ICH}$ complicent analytical method for quantitative analysis of caipsaicin using HPLC was developed and validated in present study. Methods: Critical extraction parameters like extraction time, temperature and solvent were optimized to develop an efficient method for extraction of oleoresin from capsicum fruits. A simple, rapid and stable HPLC method of capsaicin was developed using $\mathrm{C}_{18}$ (2) HPLC column, 250x4.5 $(\mathrm{mm})$, particle size $5 \mu \mathrm{m}$ and validated using various parameters viz., linearity, accuracy, precision and LOD and LOQ using methanol and HPLC grade water (65:35v/v) as mobile phase. The elution was performed at $280 \mathrm{~nm}$ with run time of $10 \mathrm{~min}$ and flow rate of 1 $\mathrm{mL} / \mathrm{min}$. Results: The optimized conditions for oleoresin extraction were found to be $40^{\circ} \mathrm{C}$ (temperature), $5 \mathrm{hr}$ (extraction time) and acetone as a solvent with highest percentage yield of $(3.7 \% \mathrm{w} / \mathrm{w})$. Furthermore, the developed HPLC method showed linear response over a concentration range of $1-9 \mu \mathrm{g} / \mathrm{mL}$ with standard regression equation $(y=4614.9 x+5344.1 .9)$ with a coefficient of correlation value, of $R^{2} 0.9974$. The validation parameter evaluated using this method showed effective and satisfactory results as per ICH Q2 (R') guidelines and percentage recovery ranged from (98\%-99.71\%) indicated good accuracy. The inter and intraday precision with relative standard deviations of capsaicin $<1 \%$, while the LOD and LOO 1.04 to $3.03 \mu \mathrm{g} / \mathrm{mL}$ respectively. The oleoresin capsicum extract was analyzed for the content of capsaicin using HPLC showing the same retention time with highly pungency value. The percentage of capsaicin in the extract was $7.30 \%$. Conclusion: The developed extraction and analytical method for capsaicin and oleoresin capsicum was accurate, precise, stable and may be useful for routine analysis of capsaicin content in capsicum fruits as well as various pharmaceutical and food preparations.

Key words: Capsaicin, HPLC, Oleoresin capsicum, Reflux method.
\end{abstract}

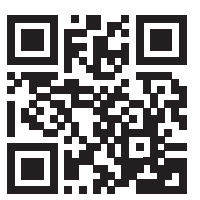

www.ijnponline.com

DOI : 10.5530/ijnp.2021.1.8

\section{INTRODUCTION}

Oleoresin capsicum (OC) is the natural lipophilic irritant and the pungent principle of capsaicinoids present in the capsicum fruits. It is an oily, deep red colored mixture of many compounds, extracted from the dried ripe fruit of different pungent varieties of capsicum plant by solid-liquid extraction. ${ }^{[1,2]}$ Extraction is the significant advance for the recuperation and purging of active elements of plant materials are generally founded on the right selection of solvents and the utilization of heat or agitation to build the dissolvability of materials and the pace of mass exchange. ${ }^{[3]}$ The selection of solvents for extraction is confined to a couple of solvents of characterized virtue permitted by national and worldwide food laws in the handling of food materials. ${ }^{[4]}$ The main pungent principle of oleoresin capsicum is mainly dependent upon at least five capsaicinoidsi.e.capsaicin, dihydrocapsaicin, nordihydrocapsaicin, homodihydrocapsaicin and homocapsaicin. ${ }^{[5]}$ Above five capsaicin, dihydrocapsaicin and nordihydrocapsaicin contribute $98 \%$ of capsaicinoids concentration and pungency of pepper. (Figure 1) summarises the chemical structure of different capsaicinoids. ${ }^{[6]}$ There are many carotenoids, which provide color to oleoresin capsicum. 5, 6-epoxide and capsorubin are carotenoids, which produce red color to paprika; while $\beta$-carotene, zeraxanthin, violoxanthin, antheroxanthin, b-cryptoxanthin and cucurbitaxanthin provide yellow color to these spices. Oleoresin capsanthin in ripe fruit is the major carotenoid contributing up to $60 \%$ of the total amount. ${ }^{[7-9]}$ Capsaicin produces a sensation of intense burning and inflammation due to the binding of transient receptor potential vanilloid 1 (TRPV1), the release of substance $\mathrm{P}$ and other cytokines present on the sensory neurons. These are also used against inflammation, analgesic against arthritis, neurogenic inflammation, antimicrobial, hypertension, ischemic heart disease, reduction of cholesterol levels and obesity. It has also been reported against the anticancer effect. Capsaicin and its analogue have provided many pharmacological effects on the gastrointestinal tract, cardiovascular, respiratory as well as sensory and thermoregulation systems. ${ }^{[10,11]}$ Exposure to OC produces inflammation, burning, swelling of the nose, throat and mucous membrane due to the binding of transient receptor potential vanilloid 1 (TRPV1). ${ }^{[12]}$ OC is biodegradable, non-toxic, non-carcinogenic produce more inflammation and onset of action as compared to tear gases 
chloroacetophenone (CN) and o-chlorobenzylidene malononitrile (CS). Scoville heat unit is used to measure the pungency of capsaicinoids. Scoville scale was developed by pharmacologist Wilbur Scoville in 1912 to measure the heat levels of chilies. The scale ranges from 0 (bell pepper) to $16,000,000$ (pure capsaicin). The pungency of capsicum fruits is classified into five levels using Scoville heat units (SHU): Non-pungent (0-700 SHU), Mildly-pungent (700-3,000 SHU), Moderately-pungent (3,000-25,000 SHU), Highly-pungent (25,000-70,000 SHU), Very High pungent $(>80,000 \mathrm{SHU}) .{ }^{[13]}$ Capsicum species have a critical function in Pharmaceutical industries. These have remedial properties, for example, effective pain killer, tonic, antiseptic, carminative and counterirritant. The species have been utilized for various diseases, for example, joint pain, neuralgia, itching, lumbago and spasms. ${ }^{[14]}$ Capsicum is also broadly utilized in the food industry as a normal seasoning and shading specialist because of its interesting sharpness, fragrance and color. ${ }^{[15]}$ It has likewise some assorted therapeutic application in inflammation, obesity, cardiovascular diseases, gastrointestinal infection and so on. In Mayan medication, capsicum is utilized for the treatment of bacterial and fungal contamination. ${ }^{[16]}$ Today as the country growing in a multi-dimensional manner, the crime rate is also increasing rapidly. This includes sexual harassment, rape against women, drug trafficking, kidnapping, murder, money laundering and other valuable throughout the world. ${ }^{[17]}$ However, frequent use of chemical irritants; accomplish self-protection against crime by causing temporary blindness, pain and irritation to skin and mucous membrane. ${ }^{[18]}$ In the present study, extraction of oleoresin capsicum from Capsicum frutescens was done by optimization of time, temperature and solvent using the reflux method. Additionally, HPLC method for quantitative analysis of capsaicin was developed as per ICH Q2 (R1) guideline viz. linearity, accuracy, precision, robustness, LOD and LOQ. Furthermore, validation of oleoresin capsicum extract was done by comparing peak, area, retention time, Scoville heat unit and content of capsaicin in the extract.

\section{MATERIALS AND METHODS}

Sample processing: Capsicum frutescens fruits were purchased from Bathinda (Punjab) (Figure 2). The fruits were sun-dried for 3 days, ground and cut into small pieces and kept in an airtight container until further process. The standard capsaicin (purity 99\%) was purchased from Sigma Aldrich USA. Methanol of HPLC grade was purchased from Finar Chemicals, Ahmedabad. Chloroform, ethanol and acetone were purchased from Loba Chemicals, Mumbai. Ultrapure Type 1 water was obtained from Millipure (India), installed at our department.

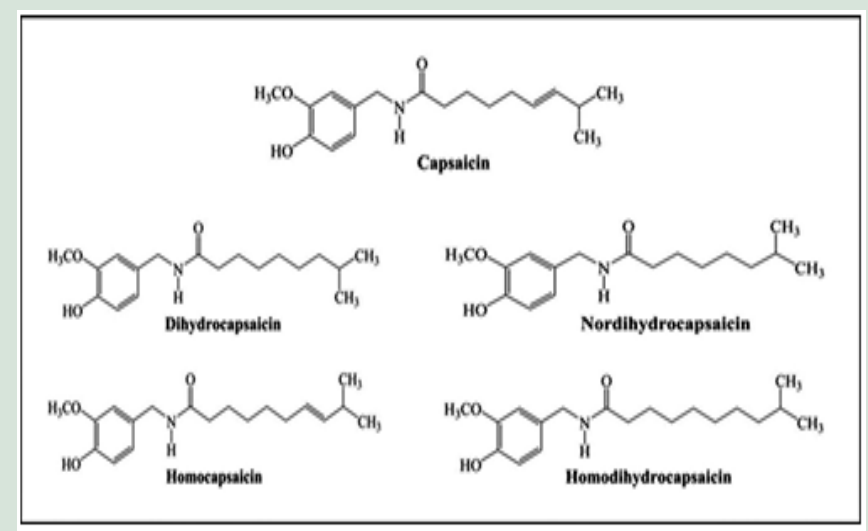

Figure 1: Chemical structure of main capsaicinoids present in oleoresin capsicum.

\section{Extraction and percentage yield of capsaicinoids using different solvent}

The effect of four different solvents (methanol, ethanol, acetone and chloroform) on percentage yield of capsaicinoids was assessed using the reflux method. The pre-treatment of dried red paprika (Capsicum frutescens) was done by drying triturated sample in a hot air oven at $60^{\circ} \mathrm{C}$ for $1 \mathrm{hr}$. The extraction of paprika was carried out using different solvents under the solid-liquid ratio. Accurately weighed (100 gm) of the paprika sample was mixed with selected solvent i.e. methanol, ethanol, acetone and chloroform in 1:4 ratio. Furthermore, the extraction parameter was studied at different temperatures $\left(30,40,50\right.$ and $\left.60^{\circ} \mathrm{C}\right)$ using a thermostatic water bath. The effect of extraction time on the analyte of interest was studied for $5 \mathrm{hr}$ (optimization data not shown here). After extraction for selected time under different temperatures, the extract was filtered and the solvent was evaporated under a rotary vacuum evaporator at $50^{\circ} \mathrm{C}$. Then the extract was collected in a round bottom flask and washed with $1 \%$ of hydrochloric acid for removal of impurities. Oleoresin capsicum was then collected in beaker and weighed to determine its percentage yield. The extraction procedure at the same operating conditions was performed in duplicate to determine the percentage yield. Figure 3 illustrates the flow chart of the extraction of oleoresin capsicum from Capsicum frutrescens.

The percentage yield of oleoresin capsicum under different experimental setup was calculated using the following formula:

$$
\% \text { Yield }=\frac{\text { Weight of oleoresin extractive }}{\text { Weight of Capsicum frutescens taken }} \times 100
$$

\section{Quantitative analysis of capsaicin using HPLC system}

Chromatographic separation was carried out on an isocratic HPLC system (Waters 1525 system) attached with a binary HPLC pump and Waters 2489 UV-visible detector. Data were recorded and processed using EMPOWER-3 software. The separation was performed on a $\mathrm{C}_{18}$ (2) column (particle size $5 \mu \mathrm{m} ; 250 \mathrm{~mm} \times 4.5 \mathrm{~mm}$ ). Water purification system for obtaining HPLC grade ultrapure type 1 water (Millipore, USA) and ultrasonicator (Amar Enterprises) were used during the chromatographic study.

\section{Conditions}

Methanol and HPLC grade water $(65: 35 \mathrm{v} / \mathrm{v})$ was used as a mobile phase for the best separation of with flow rate at $1 \mathrm{~mL} / \mathrm{min}$ of capsaicin. The temperature of the column was maintained at $37^{\circ} \mathrm{C}$ during the chromatographic separation and elution was detected at $280 \mathrm{~nm}$ for a

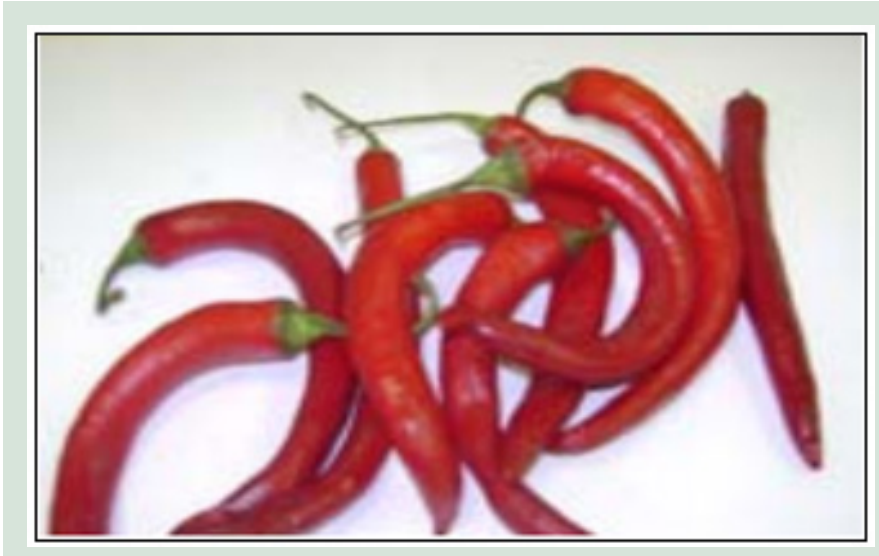

Figure 2: Fruits of Capsicum frutescens. 
run time of $10 \mathrm{~min}$. Before injecting the drug solution, the column was equilibrated for at least $45 \mathrm{~min}$. with the mobile phase.

\section{Standard solutions}

Stock working solutions of standard capsaicin $(1-9 \mu \mathrm{g} / \mathrm{ml})$ were prepared by diluting the stock solution with the desired volume(s) with methanol. All samples were passed through a $0.45 \mu \mathrm{m}$ membrane filter and the mixture was degassed using a bath sonicator. At first, blank (methanol) was injected and the chromatogram was recorded and then the standard solution(s) of capsaicin was injected separately.

\section{HPLC method development and validation Specificity}

The specificity of the HPLC method was evaluated with the injection of blank methanol in the HPLC system and peak area was measured.

\section{Linearity}

The linearity of an analytical method is its ability within a definite range to obtain results was directly proportional to the concentrations of the analyte in the sample. The calibration curve was constructed at the concentration range of $1-9 \mu \mathrm{g} / \mathrm{mL}$ by plotting concentration on $\mathrm{X}$-axis and area under curve.

\section{Accuracy}

The accuracy of the analytical method can be predicted to a measured value close to the real value. Accuracy studies were carried out in three different levels corresponding to $80 \%, 100 \%$ and $120 \%$ of target concentration i.e. $(7,9$ and $11 \mu \mathrm{g} / \mathrm{mL})$ of the standard drug. The mean value of experiment concentration was statistically analyzed using the following formula.

Mean recovery $=$ (Recovered concentration / Injected concentration $)$ ------ (2)

and \% recovery was calculated by multiply with 100

\section{Precision}

Precision, of the developed method, was assessed by assessing three different quality control levels of capsaicin at LQC (low-quality control), MQC (medium quality control) and HQC (High-quality control) at different time-intervals on the same day (i.e., intraday) and by application on subsequently day (i.e., interday) and \% RSD was calculated.

\section{Robustness}

Robustness of the developed analytical method was evaluated by minor modifications in the HPLC condition of a developed method such as a change in mobile phase ratio, temperature and flow rate and the result was expressed in \% RSD.

\section{Limit of detection (LOD) and limit of quantification (LOQ)}

The sensitivity of the method was determined by LOD and LOQ using the standard deviation of the response $(\sigma)$ and slope from the calibration curve (s) using the following formula:

$\mathrm{LOD}=3.3 \sigma / \mathrm{S}$

$\mathrm{LOQ}=10 \sigma / \mathrm{S}$

$\sigma=$ Standard deviation of the response,

$\mathrm{S}=$ Slope of relative calibration curve.

\section{Sample preparation}

\section{HPLC method for determination of capsaicin in oleoresin capsicum}

Accurately weighed (50 gm), triturated and dry samples of Capsicum frutescens and transferred into $1 \mathrm{~L}$ boiling flask. Then the volume was made up to $1 \mathrm{~L}$ with methanol. The extraction of the sample was carried out by using the reflux method. The sample was gently refluxed for $5 \mathrm{hr}$ at $90^{\circ} \mathrm{C}$ by attaching the condenser to avoid the evaporation of the solvent and cooled for a sufficient period. The extract was then transferred into a beaker and filtered to remove the impurities. Then the solvent was evaporated using a hot plate by heating at $40-50^{\circ} \mathrm{C}$ and used for capsaicin analysis.

Sample solution (oleoresin capsicum) was prepared by dissolving 10 $\mathrm{mg}$ of oleoresin capsicum into $10 \mathrm{~mL}$ of methanol to give $1000 \mu \mathrm{g} / \mathrm{ml}$ concentration. The resultant solution was then sonicated for $10 \mathrm{~min}$. This stock solution was further diluted with methanol to get a $20 \mu \mathrm{g} /$ $\mathrm{ml}$ concentration of oleoresin capsicum and passed through a $0.45 \mu \mathrm{m}$ membrane filter. The mixture was degassed using a bath sonicator for 10 min. At first, blank (methanol) was injected and a chromatogram was recorded. Then sample solution of oleoresin capsicum was injected after passing through a $0.45 \mu \mathrm{m}$ membrane filter and the sample was analyzed using the same condition of the HPLC method of standard capsaicin.

\section{Scoville Heat Unit of Capsaicinoids}

The spicy strength of oleoresin capsicum was calculated by measuring the peak areas of respective capsaicinoids from duplicate injection with the average peak area of standard capsaicin. Scoville heat unit (SHU) was calculated according to the following formula:

Capsaicin SHU = (C/A) $\left(\mathrm{C}_{\mathrm{s}} / \mathrm{WX}\right)(\mathrm{HC} / \mathrm{RC})$

Where: A, average peak area of standard;

$\mathrm{C}$, average peak area of respective capsaicinoids from duplicate injections $\mathrm{C}_{\mathrm{s}}$, concentration of standard in $\mathrm{mg} / \mathrm{mL}$

$\mathrm{WX}$, weight of sample in $\mathrm{mg} / \mathrm{mL}$

$\mathrm{HC}$, accepted heat factor of respective capsaicinoids relative to standard $(\mathrm{HC}=16.0 \mathrm{E}+06)$

$\mathrm{RC}$, response factor of respective capsaicinoids relative to standard $(\mathrm{RC}=0.89) \cdot{ }^{[19]}$

\section{Percentage of capsaicin content}

The percentage content of capsaicin was calculated by the following formula:

Capsaicin content $(\%)=\frac{\text { Total SHU }}{16 \text { al SHU }}$

\section{RESULTS}

\section{Percentage yield of capsaicinoids}

The Capsicum frutescens extracted using a solid-liquid extraction process using different solvents by the reflux method as shown in Figure 3. The oleoresin capsicum extracted with acetone showed the highest yield of oleoresin capsicum. The percentage yield of oleoresin capsicum with different solvents was shown in Table 1.

\section{HPLC method of standard capsaicin}

A representative chromatogram of $20 \mu \mathrm{g} / \mathrm{mL}$ capsaicin sample run at previously mentioned chromatographic condition and respective chromatogram and the standard plot is given in Figure 4 and Figure 5 , respectively. Table 2 summarises the selected conditions for method development. The average retention time of capsaicin was found to 
be $8.138 \mathrm{~min}$. Run time of $10 \mathrm{~min}$ was fixed for all the analysis. The calibration curve was prepared within a range of $1-9 \mu \mathrm{g} / \mathrm{mL}$ by plotting concentration on $\mathrm{X}$-axis and peak area on Y-axis. Table 3 summarises the average retention time with the average peak area of capsaicin. It indicated a linear relationship between the tested concentrations of analyte and areas of the corresponding peaks.

\section{Validation parameters}

Validation of developed analytical method was done on the basis of International Conference on Hormonization (ICH) Guidelines Q2 (R1). ${ }^{[20]}$

\section{Specificity}

Specificity of the HPLC method was shown there is no interaction of capsaicin with methanol.

\section{Linearity}

Five different concentration levels $(1 \mu \mathrm{g} / \mathrm{mL}, 3 \mu \mathrm{g} / \mathrm{mL}, 5 \mu \mathrm{g} / \mathrm{mL}, 7 \mu \mathrm{g} /$ $\mathrm{mL}$ and $9 \mu \mathrm{g} / \mathrm{mL})$ were prepared from the standard solution $(20 \mu \mathrm{g} / \mathrm{mL})$ in a triplicate manner and analysis was carried out at $280 \mathrm{~nm}$, which gave linear relationship over the concentration range of $1-9 \mu \mathrm{g} / \mathrm{mL}$ for capsaicin. From the regression analysis, the standard curve equation was found to be $y=4614.9 x+5344.1$ with a coefficient of correlation value, of 0.9974 .

\section{Accuracy}

Accuracy of the method was evaluated by the recovery test of the samples at three different levels, viz., 7, 9 and $11 \mu \mathrm{g} / \mathrm{mL}$ each with three replicates as per the ICH guidelines. ${ }^{[20]}$ Both peak area and average peak area were calculated and the result was expressed in \% recovery. The observations, as summarized in Table 4 revealed the high accuracy of the developed method.

\section{Precision}

Precision, of the developed method, was assessed by analyzing three different quality control levels of capsaicin at LQC (low-quality control), MQC (medium quality control) and HQC (High-quality control) at

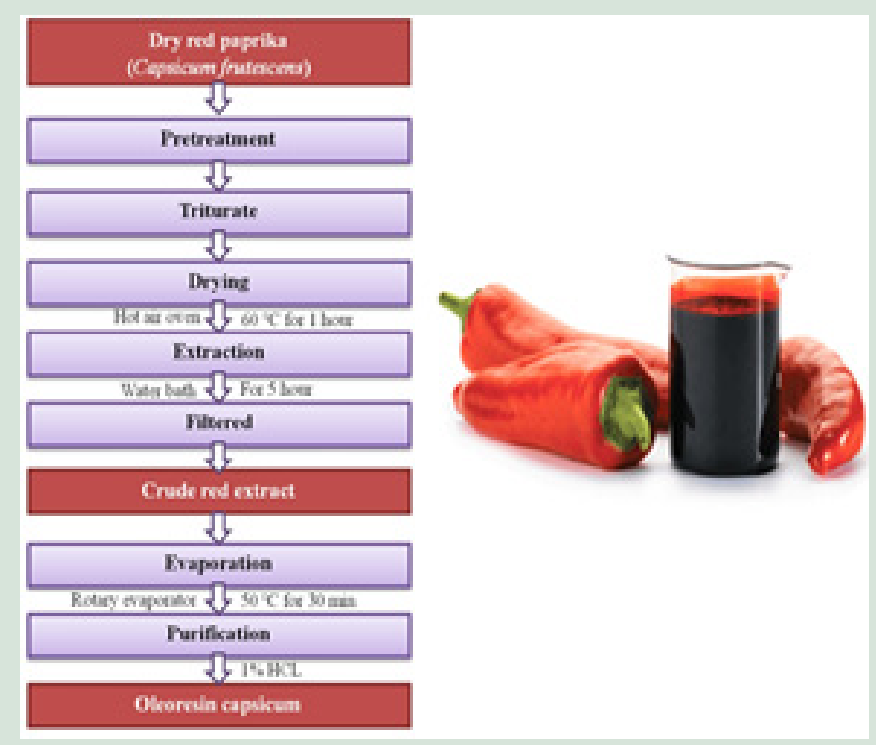

Figure 3: Extraction of oleoresin capsicum from Capsicum frutescens. different time-intervals on the same day (i.e., intraday) and by application on the next day (i.e., interday). The results depicted the analytical method as sufficiently repeatable, as indicated by the corresponding \% RSD values Table 5 illustrates inter-day and intra-day data for various quality control samples of capsaicin, with the value of $\%$ RSD, during interday (0.60-0.94) and intraday (0.56-1.01) precision studies, indicated low variability and high precision of the method performance.

\section{Robustness}

Parameters like observed concentration and \% RSD showed no appreciable difference and $\%$ RSD remained within the limit, i.e. $<1 \%$ indicate that the developed method was robust. Table 6 shows the result obtained from the robustness of capsaicin.

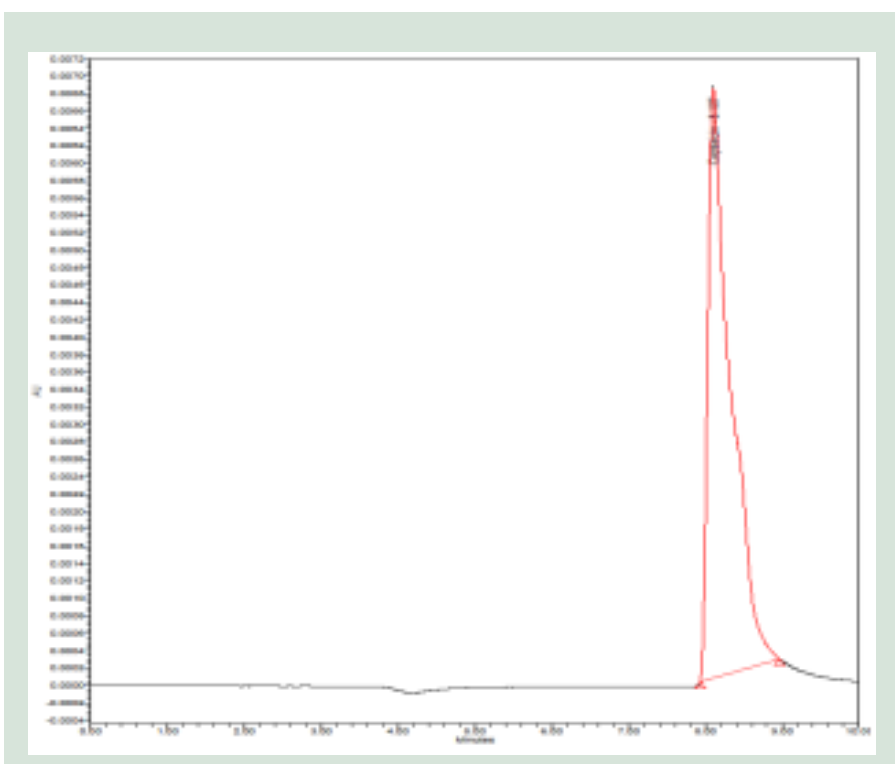

Figure 4: Chromatogram of standard capsaicin.

Table 1: Percentage yields of oleoresin capsicum using different solvent and extraction conditions.

\begin{tabular}{|c|c|c|c|c|c|}
\hline $\begin{array}{l}\text { Extraction } \\
\text { method }\end{array}$ & $\begin{array}{l}\text { Weight } \\
\text { of } \\
\text { sample }\end{array}$ & $\begin{array}{l}\text { Extracting } \\
\text { solvent } \\
(200 \mathrm{~mL})\end{array}$ & $\begin{array}{c}\text { Temperature } \\
\left({ }^{\circ} \mathrm{C}\right)\end{array}$ & $\begin{array}{l}\text { Time } \\
\text { (hr) }\end{array}$ & $\begin{array}{c}\text { Yield } \\
(\% w / w)\end{array}$ \\
\hline \multirow{4}{*}{ Reflux } & \multirow{4}{*}{$50 \mathrm{gm}$} & \multirow{4}{*}{ Ethanol } & 30 & \multirow{4}{*}{5} & 2.57 \\
\hline & & & 40 & & 2.63 \\
\hline & & & 50 & & 2.67 \\
\hline & & & 60 & & 2.72 \\
\hline \multirow{4}{*}{ Reflux } & \multirow{4}{*}{$50 \mathrm{gm}$} & \multirow{4}{*}{ Chloroform } & 30 & \multirow{4}{*}{5} & 2.48 \\
\hline & & & 40 & & 2.51 \\
\hline & & & 50 & & 2.54 \\
\hline & & & 60 & & 2.57 \\
\hline \multirow{4}{*}{ Reflux } & \multirow{4}{*}{$50 \mathrm{gm}$} & \multirow{4}{*}{ Methanol } & 30 & \multirow{4}{*}{5} & 2.99 \\
\hline & & & 40 & & 3.02 \\
\hline & & & 50 & & 3.07 \\
\hline & & & 60 & & 3.13 \\
\hline \multirow{4}{*}{ Reflux } & \multirow{4}{*}{$50 \mathrm{gm}$} & \multirow{4}{*}{ Acetone } & 30 & \multirow{4}{*}{5} & 3.3 \\
\hline & & & 40 & & 3.7 \\
\hline & & & 50 & & 3.11 \\
\hline & & & 60 & & 3.17 \\
\hline
\end{tabular}


Table 2: Selected condition for method development.

\begin{tabular}{|c|c|}
\hline Parameters & Instrument conditions \\
\hline Column & $\mathrm{C}_{18}$ (2) HPLC column, $250 \times 4.5(\mathrm{~mm})$, particle size $5 \mu \mathrm{m}$ \\
\hline Mobile phase & Methanol and water $(65: 35 \mathrm{v} / \mathrm{v})$ \\
\hline Flow rate & $1 \mathrm{~mL} / \mathrm{min}$ \\
\hline $\begin{array}{l}\text { Detection } \\
\text { wavelength }\end{array}$ & $280 \mathrm{~nm}$ \\
\hline Retention time & $8.138 \mathrm{~min}$ \\
\hline Injection volume & $20 \mu \mathrm{L}$ \\
\hline Run time & $10 \mathrm{~min}$ \\
\hline Temperature & $37^{\circ} \mathrm{C}$ \\
\hline
\end{tabular}

Table 3: Average retention time with average peak area of capsaicin.

\begin{tabular}{|c|c|c|c|c|}
\hline $\begin{array}{c}\text { S. } \\
\text { No }\end{array}$ & $\begin{array}{c}\text { Retention } \\
\text { Time }\end{array}$ & $\begin{array}{c}\text { Average Retention } \\
\text { Time }\end{array}$ & Area & $\begin{array}{c}\text { Average } \\
\text { Area }\end{array}$ \\
\hline 1. & 8.136 & & 142133 & \\
\hline 2. & 8.138 & 8.138 & 142181 & 142175 \\
\hline 3. & 8.142 & & 142212 & \\
\hline
\end{tabular}

Table 4: Accuracy data of capsaicin.

\begin{tabular}{|c|c|c|c|c|}
$\begin{array}{c}\text { Predicted } \\
\text { concentration. } \\
(\mu \mathrm{g} / \mathrm{mL})\end{array}$ & Peak Area & $\begin{array}{c}\text { Mean Peak } \\
\text { Area }\end{array}$ & $\begin{array}{c}\text { Mean } \\
\text { Recovery }\end{array}$ & $\begin{array}{c}(\%) \\
\text { Recovery }\end{array}$ \\
\hline 7 & 37611 & & & \\
\hline & 37687 & 37670 & 6.98 & 99.71 \\
\hline & 37712 & & & \\
\hline & 47137 & & & \\
\hline & 47189 & 47479 & 8.82 & 98 \\
\hline 11 & 48112 & & & \\
\hline & 62144 & & & 98.27 \\
\hline
\end{tabular}

\section{LOD and LOQ}

The LOD and LOQ for the developed HPLC method were found to be 1.04 and $3.03 \mu \mathrm{g} / \mathrm{mL}$ respectively.

\section{HPLC Method for Determination of Capsaicin in Oleoresin capsicum Extract}

The oleoresin capsicum was determined according to the same instrumentation and operating condition of standard capsaicin evaluated using the identification of peak at the same retention time. Figure 6 illustrates the chromatogram of extracted capsaicinoids showing the peak of capsaicin at the same retention time (8.179) as that of standard capsaicin (8.136).

\section{Scoville Heat Unit of Capsaicinoids and capsaicin content}

The pungent principle of oleoresin capsicum was determined in the category of very highly pungent ${ }^{[13]}$ with a Scoville heat unit of $1.16 \times 10^{6}$. The percentage content of capsaicin was found to be $7.30 \% \mathrm{w} / \mathrm{w}$.
Table 5: Intraday and intraday precision data of capsaicin.

\begin{tabular}{|c|c|c|c|}
\hline $\begin{array}{c}\text { Standard } \\
\text { concentration } \\
(\mu \mathrm{g} / \mathrm{mL})\end{array}$ & $\begin{array}{c}\text { Recovered concentration } \\
(\mu \mathrm{g} / \mathrm{mL})\end{array}$ & S.D & \\
\hline & & & \\
\hline LQC:7 & Intra-day precision \\
\hline MQC:9 & 6.72 & 0.04509 & 0.67 \\
\hline HQC: 11 & 9.16 & 0.05567 & 0.60 \\
\hline LQC: 7 & 10.81 & 0.10263 & 0.94 \\
\hline MQC: 9 & Inter-day precision & & \\
\hline HQC 11 & 6.70 & 0.03785 & 0.56 \\
\hline
\end{tabular}

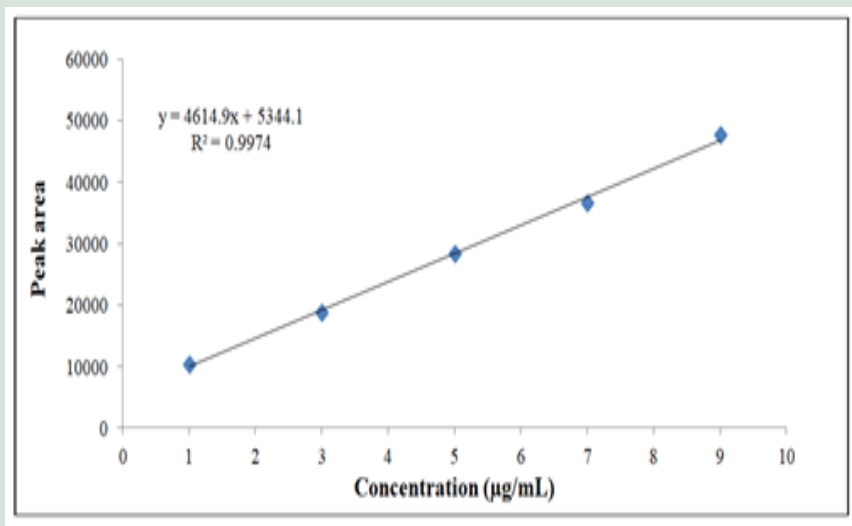

Figure 5: Standard curve of capsaicin in methanol.

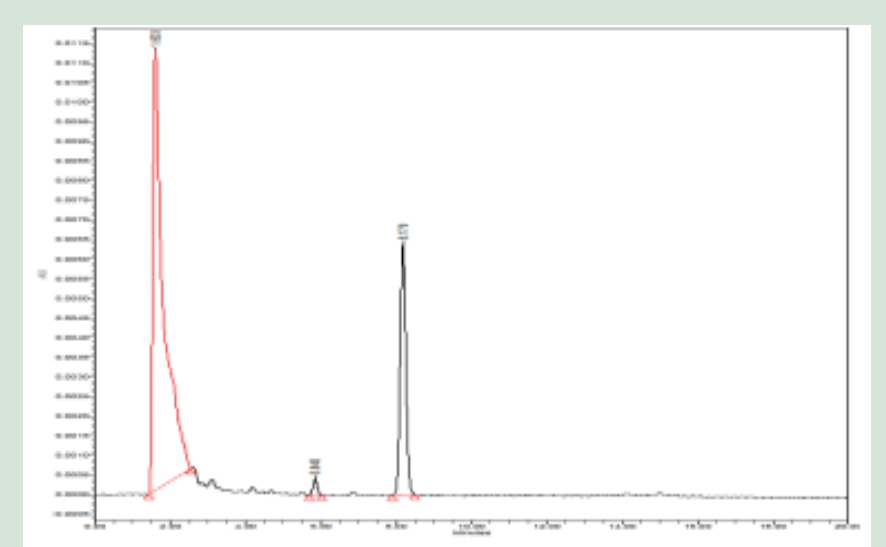

Figure 6: Chromatogram of extracted capsaicinoids showing the peak of capsaicin.

\section{DISCUSSION}

The content of capsaicin present in different varieties of capsicum fruits mainly depend upon many factors such as geographical origin, environmental condition, soil characteristics as well as extraction conditions. The current study showed fast, cheap, efficient and reproducible method for extraction of oleoresin capsicum from Capsicum frutescens. The main advantages of this study were the minimum of extraction time and increasede percentage yield as 
Table 6: Robustness data of capsaicin.

\begin{tabular}{|c|c|c|c|c|c|c|}
\hline \multicolumn{7}{|c|}{ Robustness data with change in composition of mobile phase } \\
\hline Methanol: water (v/v) & $\begin{array}{c}\text { Run } 1(\mu \mathrm{g} / \\
\mathrm{mL})\end{array}$ & $\begin{array}{c}\text { Run } 2(\mu \mathrm{g} / \\
\mathrm{mL})\end{array}$ & $\begin{array}{c}\text { Run } 3(\mu \mathrm{g} / \\
\mathrm{mL})\end{array}$ & $\begin{array}{l}\text { Mean } \\
\text { conc. }\end{array}$ & S.D & $\%$ RSD \\
\hline $64: 36$ & 4.94 & 4.88 & 4.91 & 4.91 & 0.03 & 0.61 \\
\hline $65: 35$ & 4.96 & 4.98 & 5.02 & 4.98 & 0.03 & 0.60 \\
\hline $66: 34$ & 5.01 & 4.99 & 5.03 & 5.01 & 0.02 & 0.39 \\
\hline \multicolumn{7}{|c|}{ Robustness data with change in temperature } \\
\hline Temperature & $\begin{array}{c}\text { Run } 1 \\
(\mu \mathrm{g} / \mathrm{mL})\end{array}$ & $\begin{array}{c}\text { Run } 2 \\
(\mu \mathrm{g} / \mathrm{mL})\end{array}$ & $\begin{array}{c}\text { Run } 3 \\
(\mu \mathrm{g} / \mathrm{mL})\end{array}$ & $\begin{array}{l}\text { Mean } \\
\text { conc. }\end{array}$ & S.D & $\%$ RSD \\
\hline 35 & 5.01 & 4.99 & 5.00 & 5.00 & 0.01 & 0.2 \\
\hline 37 & 4.95 & 4.97 & 4.93 & 4.95 & 0.02 & 0.40 \\
\hline 39 & 4.89 & 4.91 & 4.97 & 4.92 & 0.04 & 0.81 \\
\hline \multicolumn{7}{|c|}{ Robustness data with change in flow rate } \\
\hline Flow rate & $\begin{array}{c}\text { Run } 1 \\
\text { ( } \mu \mathrm{g} / \mathrm{mL})\end{array}$ & $\begin{array}{c}\text { Run } 2 \\
(\mu \mathrm{g} / \mathrm{mL})\end{array}$ & $\begin{array}{c}\text { Run } 3 \\
(\mu \mathrm{g} / \mathrm{mL})\end{array}$ & $\begin{array}{l}\text { Mean } \\
\text { conc. }\end{array}$ & S.D & \% RSD \\
\hline 0.9 & 5.03 & 5.01 & 5.04 & 5.02 & 0.01 & 0.19 \\
\hline 1 & 4.97 & 4.99 & 5.01 & 4.99 & 0.02 & 0.40 \\
\hline 1.1 & 4.87 & 4.83 & 4.80 & 4.83 & 0.03 & 0.62 \\
\hline
\end{tabular}

Table 7: Validation parameters of capsaicin.

\begin{tabular}{|c|c|}
\hline Validation parameters & Values \\
\hline Linearity range & $1-9 \mu \mathrm{g} / \mathrm{mL}$ \\
\hline Standard regression equation & $\mathrm{Y}=4614.9 \mathrm{x}+5344.1$ \\
\hline Correlation coefficient (R2) & 0.9974 \\
\hline Accuracy (\% recovery) & 98 to 99.71 \\
\hline Precision & $\begin{array}{c}\text { Intraday (\% RSD } 0.67 \text { to } 0.94) \\
\text { Interday (\% RSD } 0.56 \text { to } 1.01)\end{array}$ \\
\hline Robustness & Change in composition of mobile phase (\% \\
& RSD 0.39 to 0.61 \\
\hline LOD & Change in temperature (\% RSD 0.2 to 0.81$)$ \\
\hline LOQ & $1.04 \mu \mathrm{g} / \mathrm{mL}$ \\
\hline
\end{tabular}

compared to similar studies ${ }^{[21,22]}$ Various types of extraction methods for the extraction of capsaicinoids have been used for the last decades. ${ }^{[23]}$ Designing of extraction technique, selection of solvent, the volume of solvent, solubility, cost, safety profile, sample quantity, time and temperature was the main factor to achieve high extraction efficiency. ${ }^{[23]}$ Moreover, ethanol, acetone and methanol are the universal solvents in the solvent extraction of phytochemical investigation. ${ }^{[21]}$ High temperatures increases the solubility as well as extraction efficiency. ${ }^{[23]}$ Moreover, the temperatures that are very high above the boiling point of the solvent may cause solvents to be lost, leading to extracts of undesirable impurities and decomposition of components. ${ }^{[21]}$ In this study, oleoresin capsicum was successfully extracted from Capsicum frutescens (Red paprika) using the reflux method by polar solvents such as methanol, ethanol, chloroform and acetone for $5 \mathrm{hrs}$ and at different temperature $\left(30-60^{\circ} \mathrm{C}\right)$ conditions. The extracted profile of oleoresin capsicum mainly depends upon the solvent polarity, physiochemical properties of the particular solvent and different temperature conditions. Therefore oleoresin capsicum extracted using acetone as compared to other solvents for $5 \mathrm{hr}$ at $30-60^{\circ} \mathrm{C}$ had confirmed the effect of polarity on extraction efficiency as reflected by the highest percentage yield of capsaicinoids present in the oleoresin capsicum. The extraction efficiency increases with the increase in extraction time and temperature ranges. Increasing time will not affect the extraction after equilibrium of the solute is reached inside and outside the solid materials, various researchers ${ }^{[24,25]}$ performed similar study on the extraction of capsaicinoids using reflux and other extraction methods with (methanol, acetonitrile, acetone, ethanol and chloroform). Whereas, acetonitrile and ethanol were the best solvents for the extraction of capsaicin from fresh pepper fruits, while acetone was a better solvent for dried pepper fruits for high yield. Extraction of capsaicinoids from (Capsicum frutescens) using supercritical fruit extraction assisted by ultrasound, with $\mathrm{CO}_{2}$ as a solvent. But the method used was sophisticated costly and difficult to operate optimized extraction method for high percentage yield. ${ }^{[26-28]}$ As reported in present study, the reflux extraction method was more efficient than other extraction methods (Percolation, maceration and sonication). Hence reflux method can be successfully used to extract capsaicinoids from oleoresin capsicum (Capsicum frutescens) in contrast to other extraction methods because of safety, ease of operation, less requirement of solvent and highest extraction efficiency. The extracted oleoresin capsicum was highly pungent due to presence of $7.30 \%$ of capsaicin.

In present study, the analytical HPLC method to quantify capsaicin was developed at $280 \mathrm{~nm}$. The validation parameters of reported analytical method for capsaicin is summarized in Table 7. The constructed calibration curve $(1-9 \mu \mathrm{g} / \mathrm{mL})$ showed a linear response with a coefficient of correlation $R^{2}$ (0.9974), indicating a linear relationship between the concentration of analyte and the area of the corresponding peak. The result of accuracy and precision were found to be within the limit of ICH Q2 (R1) guidelines. The result of robustness studies with a minor change in method conditions, such as the composition of the mobile phase, flow rate and temperature, was robust within acceptable limits. The LOD and LOQ of the developed method were $1.04 \mu \mathrm{g} / \mathrm{mL}$ and 3.03 $\mu \mathrm{g} / \mathrm{mL}$ respectively. Identification of capsaicin using the same operating condition by comparison of the peak at the same retention time found satisfactory with that of standard capsaicin. Various analytical methods for quantification of phytochemicals and active pharmaceuticals have also been reported by our research group on similar lines. ${ }^{[29-33]}$ Thus, the developed HPLC method can be successfully applied for routine 
analysis of capsaicin in different species of capsicum fruits and also used to determine the other minor capsaicinoids once suitable standards are available.

\section{CONCLUSION}

This study highlights the optimum conditions for extraction of oleoresin capsicum from Capsicum frutescens. The reflux method developed is safe, easy to operate, utilizes less solvent volume and gives the highest percentage yield as compared to other reported extraction methods. The developed HPLC method for capsaicin and extracted oleoresin capsicum was accurate, precise, stable and may be useful for routine analysis of capsaicin content in capsicum fruits as well as various pharmaceutical and food preparations. The Scoville heat unit and capsaicin content of extracted oleoresin capsicum were also evaluated in this study to determine the pungency and capsaicin content in Capsicum frutescens extract.

The oleoresin capsicum extracted in this study can be used as coloring, flavoring agents in foods and beverages, formulation of insect, pest repellents and personnel self-defense spray.

As well as can be substituted with various capsaicin based formulations for analgesic, antifungal, anti-psoriatic activity (creams and ointments), for treatment of neuropathic pain (patch) and non-allergic rhinitis (nasal spray).

\section{ACKNOWLEDGEMENT}

Authors are thankful to Science and Engineering Research Board, Department of Science and Technology, Government of India, for providing research grant under 'Core Research Grant' scheme (CRG/2018/000425) to Dr. Ashish Baldi and research fellowship to Mr. Subh Naman.

\section{CONFLICT OF INTEREST}

The authors declare no conflict of interest.

\section{ABBREVIATIONS}

\%: Percentage; AUC: Area Under Curve; Cm: Centimetre; Conc.: Concentration; $\mathrm{C}_{\max }$ : Maximum Concentration; ${ }^{\circ}$ : Degree Celsius; $\mathbf{M g}$ : Microgram; \%w/v: per cent weight by volume; FDA: Food and Drug Administration; Fig.: Figure; GC: Gas Chromatography; GC-MS: Gas Chromatography-Mass Spectroscopy; Gm: Gram; $\mathbf{H}_{2} \mathbf{O}$ : Water; HCl: Hydrochloric Acid; Hr: Hours; ICH: International Council for Harmonisation; IP: Indian Pharmacopoeia; IR: Infra-Red; IU: International Unit; $\mathbf{L D}_{50}$ : Lethal Dose; LOD: Limit of Detection; LOQ: Limit of Quantification; Mg: Milligram; MP: Melting point; $\mathbf{m L}$ : Millilitre; PPM: Parts Per Millions; QC: Quality Control; $\boldsymbol{R}^{2}$ : Coefficient of Correlation; SCU: Scoville Colouring Unit; SD: Standard Deviation; Sec: Seconds; SHU: Scoville Heat Unit; UV: Ultraviolet; \%w/w: per cent weight by weight; Nm: Wavelength $\mathrm{NaOH}$ : Sodium Hydroxide; OC: Oleoresin Capsicum; HPLC: High Pressure Liquid Chromatography; HPTLC: High-Performance Thin Layer Chromatography; max.: maximum; mm: millimetre; MT: Metric ton; NMPB: National Medicinal Plants Board; $\boldsymbol{R}_{f}$ Retention factor; TCM: Traditional Chinese Medicine; TLC: Thin Layer Chromatography; UV: Ultraviolet; WHO: World Health Organization.

\section{REFERENCES}

1. Wesolowska A, Jadczak D, Grzeszczuk M. Chemical composition of the pepper fruit extracts of hot cultivars Capsicum annum L. Acta Sci Pol Hortorum Cultus. 2011;10(1):171-84

2. Fernandez-Ronco MP, Gracia I, DeLucas A, Rodriguez JF. Measurement and modeling of the high-pressure phase equilibria of $\mathrm{CO}_{2}$-Oleoresin Capsicum. J
Supercrit Fluids. 2011;57(2):112-9.

3. Wu J, Lin L, Chau FT. Ultrasound-assisted extraction of ginseng saponins from ginseng roots and cultured ginseng cells. Ultrason Sonochem. 2001;8(4):34752

4. Pawar HA, Gavasane AJ, Choudhary PD. A Novel and simple approach for extraction and isolation of curcuminoids from turmeric rhizomes. Nat Prod Chem Res. 2018;6(300):2

5. Kraikruan W, Sukprakarn S, Mongkolporn O, Wasee S. Capsaicin and dihydrocapsaicin contents of Thai chili cultivars. J Nat Sci. 2008;42(2):611-6.

6. Chuichulcherm S, Prommakort S, Srinophakun P, Thanapimmetha A. Optimization of capsaicin purification from Capsicum frutescens Linn. with column chromatography using Taguchi design. Ind Crops Prod. 2013;44:473-9.

7. Hornero-Mendez D, Costa-Garcia J, Minguez-Mosquera MI. Characterization of carotenoid high-producing Capsicum annum cultivars selected for paprika production. J Agric Food Chem. 2002;50(20):5711-6.

8. Parvez GM. Current advances in pharmacological activity and toxic effects of various Capsicum species. Int J Pharm Sci Res. 2017;8(5):1900-12.

9. Park YK, Park KC, Park CH, Kim NS. Chromosomal localization and sequence variation of 5S rRNA gene in five Capsicum species. Mol Cells. 2000;10(1):18 24.

10. Sharma SK, Vij AS, Sharma M. Mechanisms and clinical uses of capsaicin. Eur J Pharmacol. 2013;720(1-3):55-62.

11. Yang D, Luo Z, Ma S, Wong WT, Ma L, Zhong J, et al. Activation of TRPV1 by dietary capsaicin improves endothelium-dependent vasorelaxation and prevents hypertension. Cell Metab. 2010;12(2):130-41.

12. Matthews PJ, Aziz Q, Facer P, Davis JB, Thompson DG, Anand P. Increased capsaicin receptor TRPV1 nerve fibres in the inflamed human oesophagus. Eur J Gastroenterol Hepatol. 2004;16(9):897-902.

13. Othman ZA, Ahmed YB, Habila MA, Ghafar AA. Determination of capsaicin and dihydrocapsaicin in Capsicum fruit samples using high performance liquid chromatography. Molecules. 2011;16(10):8919-29.

14. Yaldiz G, Ozguven M, Sekeroglu N. Variation in capsaicin contents of different Capsicum species and lines by varying drying parameters. Ind Crops Prod. 2010;32(3):434-8

15. Nag M, Chanda J, Biswas $R$, Al-Dhabi NA, Duraipandiyan $V$, Banerij $P$, et al. Validation of capsaicin in Indian capsicum species through RP-HPLC. Indian J Pharm Educ Res. 2017;51(2):337-42.

16. Bischoff H. Bekämpfung der Dauerausscheidung von Bazillen mittels Yatren (Tryen). DMW-Deutsche Medizinische Wochenschrift. 1913;39(38):1834-7.

17. Bhattacharyya R. Street violence against women in India: Mapping prevention strategies. Asian Soc Work Policy Rev. 2016;10(3):311-25.

18. Delamanche S, Desforges P, Morio S, Fuche C, Calvet JH. Effect of oleoresin capsicum (OC) and ortho-chlorobenzylidene malononitrile (CS) on ciliary beat frequency. Toxicology. 2001;165(2-3):79-85.

19. Babu PS, Guravaiah M, Hatti I, Srikanth K. Qualitative analysis of capsaicin from chillies and chilli powder by HPLC method. Chemistry. 2014;1(6):184-94.

20. Guideline ICH. O2 (R1) (1994) Validation of analytical procedures: Text and Methodology. Proceedings of the International Conference on Harmonization, Geneva, Switzerland. Pg. 2012;(1-5).

21. Rafajlovska V, Slaveska-Raicki R, Koleva GL, Klopceska J. Spice paprika oleoresin extraction under different conditions involving acetone and ethanol. $J$ Food Agric Environ, Helsinki-Finland. 2007;65-9.

22. Riquelme N, Matiacevich S. Characterization and evaluation of some properties of oleoresin from Capsicum annuum var. cacho de cabra. CYTA J Food. 2017;15(3):344-51.

23. Jaren-Galan M, Mínguez-Mosquera MI. Quantitaive and qualitative changes associated with heat treatments in the carotenoid content of paprika oleoresins. J Agric Food Chem. 1999;47(10):4379-83.

24. Attuquayefio VK, Buckle KA. Rapid sample preparation method for HPLC analysis of capsaicinoids in capsicum fruits and oleoresins. J Agric Food Chem. 1987;35(5):777-9

25. Chinn MS, Sharma-Shivappa RR, Cotter JL. Solvent extraction and quantification of capsaicinoids from Capsicum chinense. FBP. 2011;89(4):340-5.

26. Santos $P$, Aguiar AC, Barbero GF, Rezende CA, Martínez J. Supercritical carbon dioxide extraction of capsaicinoids from malagueta pepper (Capsicum frutescens L.) assisted by ultrasound. Ultrason Sonochem. 2015;1(22):78-88

27. Kongkiatpaiboon S, Gritsanapan W. Optimized extraction for high yield of insecticidal didehydrostemofoline alkaloid in Stemona collinsiae root extracts. Ind Crops Prod. 2013;41(1):371-4

28. Dejmkova H, Morozova K, Scampicchio M. Estimation of Scoville index of hot chili peppers using flow injection analysis with electrochemical detection. J Electroanal Chem. 2018;15(821):82-6.

29. Madhavi N, Kumar D, Naman S, Singh M, Singh PA, Bajwa N, et al. Formulation and evaluation of novel herbal formulations incorporated with Amla extract for improved stability. J Drug Deliv Ther. 2019;9(4):212-21.

30. Singh M, Kumar D, Naman S, Madhavi N, Singh PA, Bajwa N, et al. Validation of Hptlc method for the simultaneous estimation of ascorbic acid and gallic acid in amla juice preparation. J Drug Deliv Ther. 2019;9(4):227-31. 
31. Singh PA, Brindavanam NB, Kimothi GP, Aeri V. Evaluation of in vivo antiinflammatory and analgesic activity of Dillenia indica f. elongata (Miq.) Miq. and Shorea robusta stem bark extracts. Asian Pac J Trop Dis. 2016;6(1):75-81.

32. Singh PA, Brindavanam NB, Kimothi GP, Verma R, Aeri V. A validated hplc method for the determination of betulin in the stem bark of Tectona grandis linn. Int J Pharm Sci Res. 2016;7(2):719-23.

33. Singh PA, Vidhu A. Physico-chemical parameters and HPTLC fingerprinting profile of Dillenia indica Miq. f. Elongata (Miq.) and Tectona grandis Linn. with reference to betulin. Int J Pharma Bio Sci. 2016;7(1):217-21.

\section{GRAPHICAL ABSTRACT}

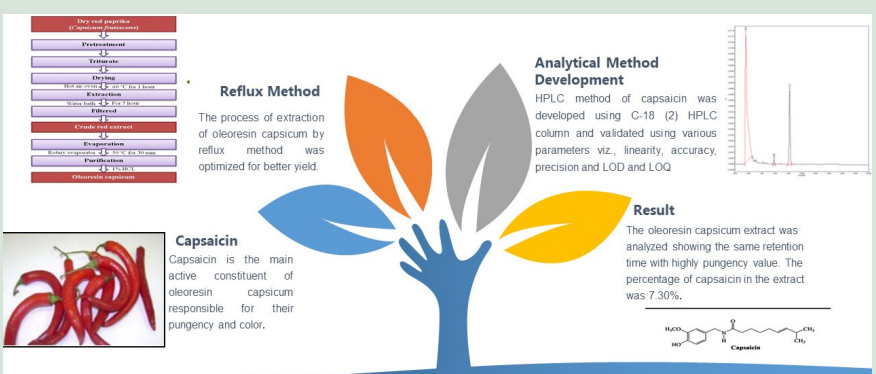

Extraction and Analytical Method for Capsaicin

\section{SUMMARY}

- Capsaicin is the main active constituent of oleoresin capsicum present in capsicum fruits and responsible for their pungency and color.

- Capsaicinoids are important phytoconstituents and hence explored for various benefits.

- Extraction of oleoresin capsicum by reflux method was optimized on the basis of percentage yield.

- Analytical method for quantitative analysis of caipsaicin using HPLC was developed and validated in present study.

- Developed extraction and analytical method for capsaicin and oleoresin capsicum was accurate, precise, and stable. This may be useful for routine analysis of capsaicin content in capsicum fruits as well as various pharmaceutical and food preparations.

\section{ABOUT AUTHORS}
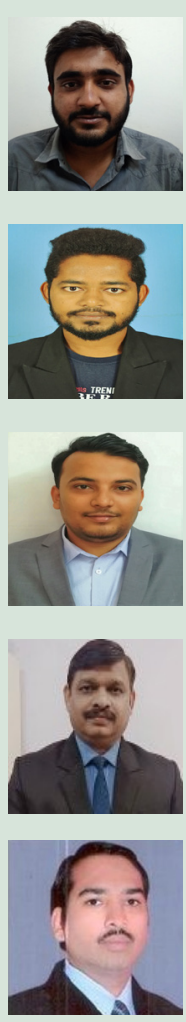

Shubham Sharma is a M. Pharm Scholar at Department of Pharmaceutical Sciences \& Technology, MRSPTU, Bathinda, Punjab.

Ranjit Singh Kushwaha is currently working as Research Fellow in a research project funded by National Medicinal Plant Board, Ministry of AYUSH, Govt. of India under the guidance of Prof. Ashish Baldi at Department of Pharmaceutical Sciences \& Technology, MRSPTU, Bathinda, Punjab.

Subh Naman is currently DST-SERB Junior Fellow and also pursuing PhD at Department of Pharmaceutical Sciences \& Technology, MRSPTU, Bathinda, Punjab under the guidance of Prof. Ashish Baldi. With several best presentation and research award, he is presently working on quality certification of spices using machine learning.

Dr. Umesh Kumar Patil, is currently working as a Professor at Dr. Harisingh Gour University, Department of Pharmaceutical Sciences and Technology Sagar, Madhya Pradesh, India. He has more than 200 national and international publications with $>3300$ cumulative citations. With several awards and scientific acclaims, he is an active researcher in herbal drugs technology and product development.

Dr. Ashish Baldi, is Professor and founder head of Department of Pharmaceutical Sciences \&Technology, MRSPTU, Bathinda, Punjab. Recently he was featured in top $2 \%$ best scientists in 'Pharmacy and Pharmacology' as per survey of Stanford University, USA. He has 05 patents, 03 technology transfers, 06 books, 4 special issues with Bentham Science Publishers along with over 125 national and international publications with cumulative impact factor of $>110$. He has presented more than 150 papers at conferences/seminars in India and abroad, and has several best paper awards to his credit. He has completed several research projects for various government agencies and is currently supervising 6 government funded projects including DST, ICMR, ICSSR, Ministry of AYUSH, etc.

History: Submission Date: 31-12-2020; Review Completed: 13-01-2020; Accepted Date: 01-02-2021

Cite this article: Sharma S, Kushwaha SR, Naman S, Patil UK, Baldi A. Optimized Extraction of Oleoresin Capsicum and Analytical Method Validation for Capsaicin using HPLC. Indian J Nat Prod. 2021;35(1):38-45. 